\title{
Condição microbiológica após antissepsia da genitália externa em éguas
}

Microbiological condition after antisepsis of reproductive tract in mares

\author{
Victoria Kanadani Campos Poltronieri ${ }^{{ }^{*}}$, Felipe Sperandio de Mattos ${ }^{1}$, Maria Aparecida \\ Scatamburlo Moreira ${ }^{1}$, Ytalo Galineri Henriques Schuartz ${ }^{1}$, Iara Magalhães Ribeiro ${ }^{1}$, Bruna \\ Waddington de Freitas ${ }^{1}$
}

${ }^{1}$ Universidade Federal de Viçosa- UFV, Departamento de Veterinária-DVT, Viçosa, MG, Brasil Av. Peter Henry Rolfs, s/n - Campus Universitário, Viçosa, MG, 36570-900

\section{Resumo}

A endometrite é a principal responsável pela diminuição nas taxas de fertilidade e recuperação embrionária em éguas e em parte, pode ser associada a contaminações por falhas na antissepsia das biotécnicas reprodutivas aplicadas à espécie. O objetivo deste trabalho foi avaliar os níveis de contaminação decorrentes de diferentes protocolos de antissepsia da genitália externa de éguas doadoras de embrião. Éguas sadias tiveram a vulva higienizada conforme um dos três grupos experimentais: (G1) sabão de côco; (G2) detergente neutro e (G3) clorexidina degermante 2\%. Foi realizada a coleta de material da região da vulva, vestíbulo e útero com auxílio de $s w a b$ estéril. As amostras foram processadas com objetivo de se determinar os principais microgranismos presentes, além da avaliação de Unidades Formadoras de Colônia (UFC). O G1 mostrou-se mais efetivo quanto à redução nas contagens de UFC em todas amostras. Por outro lado, G2 apresentou eficiência de $62 \%$, sendo o tratamento menos eficiente na redução da contaminação das diferentes regiões avaliadas. A escolha adequada do agente sanitizante utilizado na higienização de períneo previamente a intervenções ginecológicas são de suma importância afim de se evitar contaminações ascendentes que levem a endometrites.

Palavras-Chave: Equino, cavalos, subfertilidade, infecção uterina

Abstract

Endometritis is mainly responsible for the decrease in fertility and embryonic recovery rates in mares and, in part, it can be associated with contaminations due to failures in the antisepsis of reproductive biotechniques applied to the specie. The objective of this study was to evaluate the levels of contamination resulting from different protocols for antisepsis of the external genitalia of embryo donor mares. Healthy mares had their vulva sanitized according to one of the three experimental groups: (G1) coconut soap; (G2) neutral detergent and (G3) 2\% chlorhexidine degerming. It was made the collection of material from the vulva, vestibule and uterus region with the aid of a sterile swab. The samples were processed in order to determine the main microorganisms present, in addition to the evaluation of Colony Forming Units (CFU). G1 was more effective in reducing CFU counts in all samples. On the other hand, G2 showed an efficiency of $62 \%$, being the treatment less efficient in reducing contamination in the different regions evaluated. The proper choice of the sanitizing agent used to clean the perineum prior to gynecological interventions is of paramount importance in order to avoid ascending contamination that lead to endometritis.

Keywords: Equine, horses, subfertility, uterine infection

\section{Introdução}

Um dos maiores problemas encontrados na reprodução dos equinos é a subfertilidade ou infertilidade das fêmeas. Dentre as patologias reprodutivas que geram esta condição, a endometrite é a mais comum, provocando um impacto negativo significativo sobre os índices reprodutivos (Schöniger; Schoon, 2020). Tal condição se instala quando falha ou incompetência em qualquer um dos mecanismos naturais de defesa uterina ocorrem (Leblanc, 2003), sejam eles físicos, imunológicos ou linfáticos (Mattos et al., 2003). As éguas acometidas podem apresentar dificuldade para gestar, perdas embrionárias precoces, abortos no terço médio da gestação, placentites e nascimento de potros sépticos (LeBlanc e Causey, 2009).

Correspondência: victoria.poltronieri@ufv.br Recebido: 10 de abril de 2021

Aceito: 08 de julho de 2021 
A maioria dos processos inflamatórios que acometem o endométrio da fêmea equina são causados por agentes infecciosos (Siemieniuch et al., 2017). Isso se deve principalmente a uma disbiose, associada a contaminação do trato reprodutivo por agentes patogênicos oportunistas (Rasmussen et al., 2015). Agentes bacterianos são os principais causadores de endometrites na espécie, com prevalência de 25 a 60\% (Traub-Dargatz et al., 1991). As bactérias mais comumente isoladas do útero de tais fêmeas incluem Streptococcus equi zooepidemicus ( $\beta$ hemolítico), Escherichia coli, Staphylococcus aureus, Klebsiella pneumoniae e Pseudomonas aeruginosa (Ferris et al., 2016).

Em decorrência desse quadro, éguas portadoras de endometrite clínica ou subclínica representam um grande impacto negativo quanto à aplicação de biotecnologias reprodutivas, como em programas de transferência de embriões (TE) (Squires e Hon 2009; Jacob et al., 2010). A inserção de fêmeas acometidas por endometrite nos programas de TE gera reduções de aproximadamente 40-45\% nas taxas de recuperação embrionária (Foss et al., 1999; Squires et al., 1999), comprometendo o rendimento de planteis especializados por aumentar os custos com tratamentos nem sempre efetivos.

Geralmente, éguas doadoras de embrião apresentam uma incidência maior de problemas uterinos por serem submetidas à excessiva manipulação do trato genital. O processo de inseminação artificial e transferência de embriões podem carrear bactérias e fungos da microbiota vaginal para dentro do útero, em função da manipulação direta de sua genitália interna (Squires, 2013). A contaminação uterina pode ser ainda mais intensa a depender da forma de higienização da genitália externa praticada pelo profissional responsável pelo procedimento. Em função disso e, associado ao aumento considerável da aplicação das biotécnicas da reprodução na criação de equinos, propõe-se com o presente estudo a avaliação do efeito de diferentes sanitizantes utilizados rotineiramente na higienização da genitália externa sobre a microbiota vaginal e uterina de éguas candidatas a programas de transferência de embriões.

\title{
Material e Métodos
}

\author{
Animais \\ Três éguas sadias, com boa conformação perineal e histórico reprodutivo normal, da raça \\ Mangalarga Marchador, com idade entre 4 a 20 anos, provenientes do Departamento de Veterinária da \\ Universidade Federal de Viçosa foram utilizadas. Todos os procedimentos foram realizados conforme \\ recomendações da Sociedade Internacional de Transferência de Embriões, visando mimetizar a rotina \\ executada por profissionais atuantes no campo. As éguas foram submetidas à rufiação e acompanhamento \\ ultrassonográfico para determinação do estro. A coleta de material se deu na ocasião da observação de \\ edema endometrial e presença de um ou mais folículos pré-ovulatórios (diâmetro $>30 \mathrm{~mm}$ ). Todas as \\ éguas foram submetidas a todos os tratamentos com os diferentes agentes e distribuídas aleatoriamente, \\ em quadrado latino $3 \times 3$, conforme os grupos experimentais abaixo: \\ Grupo 1: higienização realizada mediante uso de sabão de côco; \\ Grupo 2: higienização realizada mediante uso de detergente neutro; \\ Grupo 3: higienização realizada mediante uso de clorexidina degermante $2 \%$. \\ Amostras foram coletadas de diferentes regiões da genitália feminina de cada égua para \\ avaliação microbiológica, conforme segue: \\ - Swab da vulva pré-higienização; \\ - Swab de vulva (fossa clitoriana) e vestíbulo e pós-higienização; \\ - Exame bacteriológico do conteúdo proveniente do lavado intrauterino.
}

\section{Coleta de amostras}

Previamente à aplicação dos tratamentos, os animais foram contidos em troncos de contenção individuais, onde foi possível a suspensão da cauda e proteção dos pelos. A região perineal de todos os animais foi enxaguada com água corrente em abundância, para retirada do excesso de sujidades. Após a secagem da região, amostras para avaliação microbiológica da vulva (fossa clitoriana) e vestíbulo pré higienização foram coletadas. Para tanto, swabs estéreis foram utilizados. A obtenção de amostras provenientes de vestíbulo se deu mediante utilização de espéculo de Polansky. Após a primeira coleta, a higienização da região perineal foi realizada. A lavagem da região com os diferentes sanitizantes contidos nos grupos 1,2 e 3 foi realizada três vezes, de forma a se retirar todos os detritos presentes. Após enxague com água em abundância e secagem com papel toalha, um pedaço de algodão umedecido com solução 
salina estéril foi utilizado para limpar o interior da fossa clitoriana. Novas amostras de vulva e vestíbulo provenientes da mesma área onde se deu a coleta da amostra pré higienização foram obtidas.

Para amostragem de conteúdo uterino, optou-se por realizar o procedimento de lavado intrauterino em baixo volume. Com auxílio de luva de palpação retal, infundiu-se no útero da égua 250 $\mathrm{mL}$ de solução Ringer Lactato por meio de sonda estéril do tipo bivona. Para tanto, a sonda foi posicionada dentro do útero a partir de palpação transvaginal mediante acesso à cérvix. Após a sifonagem do fluido, o útero foi massageado via palpação transretal, de forma a obter exposição da maior parte da superfície uterina. O conteúdo recuperado foi acondicionado em frasco estéril e posteriormente centrifugado a 400 g por 10 minutos. Após o término da centrifugação, a maior parte do sobrenadante foi descartada, restando apenas $2 \mathrm{~mL}$ e o sedimento, que foi então ressuspendido. Um $s w a b$ estéril foi mergulhado no conteúdo resultante e armazenado em tubo de ensaio estéril contendo solução salina à $0,9 \%$. Os tubos foram imediatamente fechados, identificados e destinados à análise microbiológica.

\section{Cultura Bacteriológica}

As amostras para avaliação microbiológica foram semeadas em meios de ágar sangue, (ágar base acrescido de $8 \%$ de sangue ovino desfibrinado) e incubadas em aerobiose a $37^{\circ} \mathrm{C}$ por um período de observação de 36 horas. Colônias semelhantes morfologicamente bem como em maiores contagens de UFC foram replicadas e isoladas em ágar EMB. Para o isolamento, características de crescimento de colônias em placa, como produção de hemólise, pigmento e características morfotintoriais utilizando o método de coloração pela técnica de Gram foram observadas. A contagem das Unidades Formadoras de Colônia (UFC) foi realizada de acordo com Reilas e Katila (2002).

\section{Análise Estatística}

Optou-se pela análise estatística descritiva por meio da distribuição das frequências relativa e absoluta para os achados microbiológicos e identificação dos agentes formadores de colônia.

\section{Resultados}

De acordo com o cultivo do material obtido semeado em placas de ágar sangue, foi possível caracterizar 20 tipos de colônias morfologicamente distintas, de forma que somente 6 foram classificadas como gram-negativas. $\mathrm{O}$ tratamento à base de sabão de coco mostrou-se mais efetivo quanto a redução nas contagens de UFC em todas as amostras, tendo em 100\% das avaliações demonstrado ausência de crescimento significativo em placa após exame bacteriológico. Por outro lado, o grupo 2 apresentou eficiência de $62 \%$, sendo o tratamento menos eficiente dentre os testados. Nas tabelas 1 e 2 os resultados de contagem de UFC e observação das colônias de maior isolamento em vestíbulo, fossa clitoriana e útero são expostas.

Tabela 1. Número de Unidades Formadoras de Colônias (UFC/mL) para amostras tratadas em diferentes pontos de coleta na genitália de éguas.

\begin{tabular}{ccccccc}
\hline Tratamento & Animal & Coleta & Pré & Fossa & Vestíbulo & Útero \\
\hline 1 & 1 & 1 & 25000 & 0 & 0 & 0 \\
1 & 3 & 2 & 590 & 0 & 0 & 0 \\
1 & 2 & 3 & 78000 & 0 & 0 & 0 \\
2 & 2 & 1 & 8000 & 10600 & 0 & 9000 \\
2 & 1 & 2 & 10300 & 0 & 0 & 0 \\
2 & 3 & 3 & 10400 & 800 & 6500 & 0 \\
3 & 3 & 1 & 500 & 0 & 0 & 440 \\
3 & 2 & 2 & 62000 & 1500 & 0 & 0 \\
3 & 1 & 3 & 410 & 0 & 380 & 0 \\
\hline
\end{tabular}

Distribuição das coletas em quadrado latino $3 \times 3$.

Tratamentos: 1 . sabão de côco; 2 . detergente neutro e 3 . clorexidina degermante $2 \%$.

Locais de coleta: fossa clitoriana pré (pré) e pós higienização (fossa), vestíbulo e útero.

A fossa clitoriana, nos momentos pré e pós higienização apresentou maiores taxas de contaminação, observadas pela elevada contagem de UFC's (Tab.1). A maior contagem, entretanto, foi 
Poltronieri et al. Condição microbiológica após antissepsia da genitália externa em éguas.

observada em placa semeada com swab de fossa clitoriana (10600 UFC/mL) quando detergente foi utilizado.

Todos os desinfetantes empregados foram eficientes na eliminação de Pseudomonas aeruginosa e Streptococcus equi da fossa clitoriana. Quanto à contaminação da prega vestíbulo-vaginal, todas as éguas apresentaram contaminação com Klebsiella pneumoniae e ou Streptococcus equi quando higienizadas com detergente ou clorexidine, de forma que a contaminação se manteve no útero em 2 dos 3 lavados pré-higienizados com clorexidine e em 1 dos 3 lavados pré-higienizados com detergente (Tab. 2)

Tabela 2. Distribuição de colônias de Klebsiella pneumoniae (B), Streptococcus equi (C), Pseudomonas aeruginosa (J) e Escherichia coli (U) de acordo com características de crescimento em placa para amostras tratadas em diferentes pontos de coleta na genitália de éguas.

\begin{tabular}{ccccccc}
\hline Tratamento & Animal & Coleta & Pré & Fossa & Vestíbulo & Útero \\
\hline 1 & 1 & 1 & BC & - & - & - \\
1 & 3 & 2 & BU & - & CU & CU \\
1 & 2 & 3 & BCU & B & - & - \\
2 & 2 & 1 & J & B & BJ & BJ \\
2 & 1 & 2 & BJU & - & C & - \\
2 & 3 & 3 & BCU & - & BC & - \\
3 & 3 & 1 & B & - & B & B \\
3 & 2 & 2 & CJU & B & BCU & BCU \\
3 & 1 & 3 & BC & - & C & - \\
\hline
\end{tabular}

Distribuição das coletas em quadrado latino $3 \times 3$.

Tratamentos: 1 . sabão de côco; 2 . detergente neutro e 3 . clorexidina degermante $2 \%$.

Locais de coleta: fossa clitoriana pré (pré) e pós higienização (fossa), vestíbulo e útero.

\section{Discussão}

Éguas doadoras de embrião apresentam maior incidência de problemas uterinos por serem submetidas à frequente manipulação do trato genital em função dos procedimentos de inseminação artificial, coleta de material uterino, infusões e transferência de embriões (Castro Chaves, 2011). A abertura manual da cérvix combinada com a infusão intrauterina de fluido durante a fase luteal do ciclo estral, facilita a entrada de agentes patogênicos no útero, podendo levar à ocorrência de endometrites (Koblischke et al., 2008), que reduzem as taxas de fertilidade e recuperação embrionária e podem, ao menos em parte, estar associadas a contaminações por falhas na antissepsia das técnicas (Campbell, 2014). Nesse sentido, estudos voltados para o controle microbiológico dos procedimentos aplicados na TE são de extrema valia.

Por muitos anos foi amplamente aceito que o trato reprodutivo feminino de mamíferos era estéril (Baker et al., 2018; Heil, et al., 2019). Estudos em humanos hipotetizaram que essa esterilidade seria mantida pelo tampão cervical, que forneceria uma barreira impermeável à ascensão bacteriana da vagina (Quayle, 2002), sendo esta suposição contestada por vários estudos ao final da década de 1980 (Kunz et al., 1997; Hansen et al., 2014). A presença de um microbioma uterino também foi relatada em modelos animais, principalmente em vacas, sendo o impacto do microbioma uterino na fertilidade uma questão chave em pesquisas contemporâneas (Carneiro et al., 2016; Moore et al., 2017; Parnell et al., 2017; Yang et al., 2017).

A função do microbioma no trato reprodutivo ainda não é totalmente compreendida, principalmente quando comparado à microbiota intestinal, que tem sido estudada de forma mais extensa. Vários estudos com foco na microbiota intestinal têm mostrado que os microrganismos contribuem para o desenvolvimento da imunidade e que a colonização comensal é essencial para atingir um estado imune básico saudável (Costa e Weese, 2018).

Embora a antissepsia prévia a procedimentos ginecológicos tenha sido associada a uma redução geral nas infecções, a contaminação do local do procedimento é inevitável (ACOG Committee on Practice Bulletins-Gynecology). Estudos indicam que para a maioria das infecções após esses procedimentos, a fonte de patógenos é a pele ou vagina da paciente (Eyk et al., 2012; Pereira et al., 2016). Desse modo, a adequada higienização do períneo previamente a qualquer intervenção ginecológica, de forma a se reduzir a carga microbiana presente na região, é de fundamental importância para que possíveis contaminações ascendentes sejam evitadas (Ferris, 2016).

No presente estudo, todas as amostras obtidas de fossa clitoriana pré higienização demonstraram crescimento bacteriano em placa (Tab. 1). Em convergência ao revisado por Canisso et al. (2020), 
colônias características de Klebsiella pneumoniae (B), Streptococcus equi (C), Pseudomonas aeruginosa (J) e Escherichia coli (U) foram isoladas da genitália externa de todas as éguas previamente a higienização (Tab. 2), o que explica a frequente presença desses agentes nas demais porções da genitália avaliadas.

Apesar do crescimento bacteriano em placa esperado para os swabs pré higienização de fossa e vestíbulo, o mesmo não era esperado para útero, uma vez que este tende a manter um microbioma comensal estável (Heil et al., 2019). Entretanto, significantes contagens de UFC foram observadas em amostras de lavado uterino quando clorexidina degermante a $2 \%$ ou detergente foram utilizados, demonstrando que o uso desses não atuou sobre a contaminação uterina. Altas contagens de colônias em placa mesmo em regiões de fossa clitoriana e vestíbulo não eram esperadas após o procedimento de higienização. Porém, os resultados das análises de crescimento em placa diferiram-se, mostrando que o agente utilizado para lavagem interfere na condição microbiológica da genitália interna das éguas tratadas.

Quando avaliado o assentimento entre os microorganismos encontrados no útero e demais porções do trato genital (fossa e/ou vestíbulo), observou-se convergência independentemente do agente sanitizante utilizado. Klebsiella pneumoniae, Streptococcus equi, Pseudomonas aeruginosa e Escherichia coli foram novamente as bactérias mais observadas. Tal achado corrobora com a hipótese de que a contaminação uterina se dê principalmente pela migração ascendente via vagina (Moreno e Franasiak, 2017), reforçando assim a importância de uma adequada antissepsia prévia a qualquer acesso transcervical.

A microbiota genital é sabidamente composta por grande variedade de microorganismos não patogênicos e patogênicos, que tendem a permanecer em equilíbrio. Entretanto, tal composição não é constante, sofrendo variações mediante a fatores exógenos e endógenos (Priestlley et al., 1997; Eschenbach et al., 2000). As modificações podem aumentar ou diminuir as vantagens seletivas para microrganismos específicos (Linhares et al., 2009). O uso corriqueiro de agentes desinfetantes, por exemplo, pode alterar sua composição (Dascanio, 2014). Dessa forma, o emprego de sabões neutros para lavagem do períneo, como o sabão de côco, deve ser preconizado. Como demonstrado no presente estudo, tal agente apresenta boa efetividade no controle microbiano, tendo atuado positivamente sobre as contagens de UFC em todas as amostras (Tab. 1).

Colônias de Escherichia coli foram caracterizadas em placas de fossa clitoriana pré higienização, vestíbulo e útero, mediante o tratamento 1 (apesar de contagens não significativas em placa) e 3 (Tab.2). Em nenhum animal, colônias características de $E$ coli foram observadas após uso de detergente. Variações como essas, podem ser explicadas pela eficiência seletiva dos agentes sanitizantes sobre determinados grupos de microrganismos. Os detergentes reduzem a carga microbiana através da remoção de sujeiras e matérias orgânicas. Tais substâncias apresentam em sua composição agentes tensoativos capazes de reduzir a tensão superficial ao estar dissolvido com a água. Esses, são capazes de reduzir em aproximadamente $10^{5}$ UFC da carga microbiana (Santa Bárbara et al., 2012). Entretanto, sua capacidade bactericida é reduzida e sua eficiência está relacionada com a forma de higienização associada, o que é exemplificado pela maior contagem de UFC quando este foi utilizado.

Embora o ideal seja estabelecer um único ensaio que apresente correlação direta com o nível de contaminação, os diferentes tratamentos apresentam diferentes mecanismos de ação, que podem favorecer a contaminação ascendente ou não para determinados grupos de microrganismos. A clorexidina, por exemplo, apresenta menor ação degermante sobre bactérias gram-negativas (Kampf, 2002; Marchetti et al., 2003), o que pode ser responsável por sua baixa responsividade frente à E. coli (Tab. 2).

A partir de uma grande quantidade de pesquisas conduzidas em humanos, sabe-se que a maioria das áreas do trato reprodutivo feminino de mamíferos são colonizadas por um microbioma único. No entanto, um microbioma "padrão" do trato reprodutivo feminino saudável não foi ainda definido. A compreensão deste é complicada por fatores que influenciam o sucesso reprodutivo em fêmeas mamíferas. Saber que há uma associação consistente entre disbiose do microbioma vaginal e resultados reprodutivos desfavoráveis, e que riqueza microbiana semelhante é vista entre o óstio cervical externo e o útero em mulheres e éguas prova que mais informações sobre os microbiomas endometriais são necessárias (Benner et al., 2018; Heil et al., 2019).

\section{Conclusão}

A importância das interações entre o organismo do hospedeiro e as bactérias que ele suporta é bem estabelecida. No entanto, muitas questões permanecem em relação a como esse ambiente microbiano 
muda dentro e entre os indivíduos (Green et al., 2015). É bem conhecido que existe uma relação entre infecção e inflamação do trato reprodutivo e um desempenho reprodutivo prejudicado ou reduzido (Canisso et al., 2016). O conhecimento do microbioma do trato reprodutivo pode auxiliar na identificação de pequenas mudanças na composição dos microorganismos que o formam, o que pode não ser clinicamente perceptível, mas clinicamente importante.

No presente estudo, o sabão de coco mostrou-se o mais efetivo, com contagens não significantes de UFC em região de fossa, vestíbulo e negativas em útero, tendo eliminado Streptococcus equi, Klebsiella pneumoniae e Pseudomonas aeruginosa em todas as placas semeadas. A escolha do agente sanitizante associado à antissepsia adequada são fatores que devem ser levados em consideração na aplicação de biotécnicas reprodutivas, por influenciarem diretamente a condição microbiológica da genitália da fêmea equina.

\section{Referências}

ACOG Committee on Practice Bulletins-Gynecology. ACOG practice bulletin no. 104: antibiotic prophylaxis for gynecologic procedures. Obst Gynecol, v.113, p1180-1189, 2009.

Baker JM, Chase DM, Herbst-Kralovetz MM. Uterine microbiota: residents, tourists, or invaders? Front Immunol, v.9, p.1-16, 2018.

Benner M, Ferwerda G, Joosten I, Van Der Molen RG. How uterine microbiota might be responsible for a receptive, fertile endometrium. Hum Reprod Update, v.24, p.393-415, 2018.

Campbell ML. Embryo transfer in competition horses: Managing mares and expectations. Equine Vet Educ, v.26, p.322-327, 2014.

Canisso FI, Segabinazzi GTML, Fedorka EC. Persistent breeding-induced endometritis in mare- a multifaced challenge: from clinical aspects to immunopathogenesis and pathobiology. Internat J Mol Sci, v.21, p.1432, 2020.

Canisso IF, Stewart J, Coutinho da Silva MA. Endometritis: Managing persistent post-breeding endometritis. Vet Clin N Am Equine Pract, v.32, p.465-480, 2016.

Carneiro LC, Cronin JG, Sheldon IM. Mechanisms linking bacterial infections of the bovine endometrium to disease and infertility. Reprod Biol, v.16, p.1-7, 2016.

Castro Chaves, MMB. Study of mare vaginal microbiota with emphasis in research of Lactobacillus. Dissertação (Mestrado) - Faculdade de Medicina Veterinária e Zootecnia, Campus Botucatu, Universidade Estadual Paulista. Botucatu, p.45, 2011

Costa MC, Weese JS. Understanding the intestinal microbiome in health and disease. Vet Clin N Am Equine Pract, v.34, p.1-12, 2018.

Dascanio JJ. Tail Wrap and Preparation/Washing of the Perineum. In: Dascanio, J.J. \& Mccue, P.M. Equine reproductive procedures. Wiley Blackwell. p.10, 2014.

Eschenbach DA, Thwinn SS, Patton DL, Hooton TM, Stapleton AE, Agnew K. Influence of the normal menstrual cycle on vaginal tissue, discharge and microflora. Clinic Infect Dis, v.30, p.901-907, 2000.

Eyk NV, Schalkwyk JV. Antibiotic prophylaxis in gynaecologic procedures. J Obst Gynaecol, v.34, p.382-391, 2012.

Ferris RA. Endometritis: Diagnostic tools for infectious endometritis. Vet Clin North Am Equine Pract v.32, p.481-498, 2016.

Foss R, Wirth N, Schiltz P, Jones J. Nonsurgical Embryo Transfer in a Private Practice. Proceedings of the Annual Convention of the AAEP 1999, v.45, p.210-212, 1998.

Green KA, Zarek SM, Catherino WH. Gynecologic health and disease in relation to the microbiome of the female reproductive tract. Fertil Steril, v.104, p.1351-1357, 2015.

Hansen LK, Becher N, Bastholm S, Glavind J, Ramsing M, Kim CJ, Romero R, Jensen JS, Uldbjerg N. The cervical mucus plug inhibits, but does not block, the passage of ascending bacteria from the vagina during pregnancy. Acta Obstet Gynecol Scand, v.93, p.102-108, 2014.

Heil BA, Paccamonti DL, Sones JL. A role for the mammalian female reproductive tract microbiome in pregnancy outcomes. Physiol Genomics, v.51, p.390-399, 2019.

Jacob JCF, Santos GO, Oliveira JP, Gastal MO, Gastal EL. Evaluation of reproductive parameters in a commercial equine embryo transfer program. Anim Reprod Sci, v.121, p.305-306, 2010.

Kampf G, Rudolf M, Labadie JC, Barrett SP. Spectrum of antimicrobial activity and user acceptability of the hand disinfectant agent Sterillium Gel. J Hosp Infect, v.52, p.141-147, 2002.

Koblischke P, Kindahl H, Budik S, Aurich J, Palm F, Walter I, Kolodziejek J, Nowotny N, Hoppen 
HO, Aurich C. Embryo transfer induces a subclinical endometritis in recipient mares which can be prevented by treatment with non-steroid anti-inflammatory drugs. Theriogenology, v.70, p.1147-1158, 2008.

Kunz G, Beil D, Deiniger H, Einspanier A, Mall G, Leyendecker G. The uterine peristaltic pump normal and impeded sperm transport within the female genital tract. Adv Exp Med Biol, v.424, p.267-77, 1997.

Leblanc MM. Persistent mating-induced endometritis. In: Robinson, N.E. Current Therapy in Equine Medicine, 5.ed. St. Louis: Elsevier Science. p.234-237, 2003.

Leblanc MM, Causey RC. Clinical and subclinical endometritis in the mare: both threats to fertility. Reprod Domes Anim, v.44, p.10-22, 2009.

Linhares IM, Giraldo PC, Baracat EC. Novos conhecimentos sobre a flora bacteriana vaginal. Rev Assoc Med Bras, v.56, n.3, p.370-374, 2009.

Marchetti M, Kampf G, Finzi G, Salvatorelli G. Evaluation of the bactericidal effect of five products for surgical hand disinfection according to prEN 12054 and prEN 12791. J Hosp Infect, v.54, p.63-67, 2003.

Mattos RC, Malschitzky E, Jobim MIM. Endometrite na égua. Rev Bras Reprod Anim, v.27, p.150157,2003

Moore SG, Ericsson AC, Poock SE, Melendez P, Lucy MC. Hot topic: 16S rRNA gene sequencing reveals the microbiome of the virgin and pregnant bovine uterus. J Dairy Sci, v.100, p.4953-4960, 2017.

Moreno I. Franasiak JM. Endometrial microbiota-New player in town. Fertil Steril, v.108, p.32-39, 2017.

Parnell LA, Briggs CM, Cao B, Delannoy-Bruno O, Schrieffer AE, Mysorekar IU. Microbial communities in placentas from term normal pregnancy exhibit spatially variable profiles. Sci Rep, v.7, p.11200, 2017.

Pereira N, Hutchinson AP, Lekovich JP, Hobeika E, Elias RT. Antibiotic prophylaxis for gynecologic procedures prior to and during the utilization of assisted reproductive technologies: a systematic review. J Pathog, v.2016, p.1-8, 2016.

Priestlley CFJ, Jones BM, Dhar J, Goodwin L. What is normal vaginal flora? Genitourin Med, v.73, p.23-28, 1997.

Quayle AJ. The innate and early immune response to pathogen challenge in the female genital tract and the pivotal role of epithelial cells. J Reprod Immunol, v.57, p.61-79, 2002.

Rasmussen CD, Petersen MR, Bojesen AM, Pedersen HG, Lehn-Jensen H, Christoffersen M. Equine infectious endometritis: clinical and subclinical cases. J Equine Vet Sci, v.35, p.95-104, 2015.

Reilas T, Katila T. Proteins and enzymes in uterine lavage fluid of postpartum and nonparturient mares. Reprod Domes Anim, v.37, p.261-268, 2002.

Santa Bárbara MC, Miyamaru LL, Yano HM, Almodovar AAB, Lima RF, Auricchio MT, Bugno, A. Qualidade de saneantes e antissépticos utilizados em hospitais da rede pública. Rev Inst Adolfo Lutz, v.71, n.4, p.650-5, 2012.

Schöniger S, Schoon HA. The healthy and diseased equine endometrium: A review of morphological features and molecular analyses. Animals, v.10, n.4-625, 2020.

Siemieniuch MJ, Gajos K, Kozdrowski R, Nowak M. Advanced age in mares affects endometrial secretion of arachidonic acid metabolites during equine subclinical endometritis. Theriogenology, v.103, p.191-196, 2017.

Squires E, Mccue P, Vanderwall D. The current status of equine embryo transfer. Theriogenology, v.51, n.1, p.91-104, 1999.

Squires EL. Embryo transfer challenges and perspectives. Rev Bra Reprod Anim, v.37, p.105-107, 2013. Squires EL, Hon ACT. Changes in equine reproduction: have they been good or bad for the horse industry? J Equi Vet Sci, v.29, p.268-273, 2009.

Traub-dargatz JL, Salman MD, Voss JL. Medical problems of adult horses, as ranked by equine practitioners. JAVMA, v.198, p.1745-1747, 1991.

Yang X, Cheng G, Li C, Yang J, Li J, Chen D, Zou W, Jin SY, Zhang H, Li D, He Y, Wang C, Wang M, Wang H. The normal vaginal and uterine bacterial microbiome in giant pandas (Ailuropoda melanoleuca). Microbiol Res, v.199, p.1-9, 2017. 